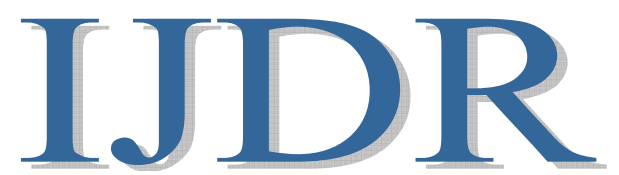

International Journal of Development Research

Vol. 11, Issue, 05, pp. 47077-47081, May, 2021

https://doi.org/10.37118/ijdr.21966.05.2021

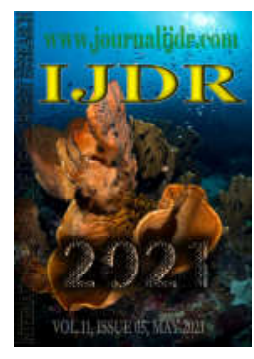

\title{
AVALIAÇÃO DO DEBRIEFING NA SIMULAÇÃO REALÍSTICA DA REANIMAÇÃO CARDIOPULMONAR PARA PROFISSIONAIS SOCORRISTAS
}

\section{*Thaísa Mariela Nascimento de Oliveira, Mara Solange Gomes Dellaroza and Eleine Aparecida Penha Martins}

Ciências da Saúde, Enfermagem, Universidade Estadual de Londrina- UEL

\begin{tabular}{l}
\hline ARTICLE INFO \\
\hline Article History: \\
Received $18^{\text {th }}$ February, 2021 \\
Received in revised form \\
$20^{\text {th }}$ March, 2021 \\
Accepted $28^{\text {th }}$ April, 2021 \\
Published online $22^{\text {th }}$ May, 2021 \\
\hline
\end{tabular}

Key Words:

Simulação; Simulação de paciente;

Reanimação cardiopulmonar; Socorristas.

\begin{abstract}
Objetivo: avaliar a contribuição do debriefing associado à simulação realística da reanimação cardiopulmonar para profissionais socorristas. Método:estudo observacional transversal, realizado com 41 socorristas do Serviço de Atendimento Móvel de Urgência. A coleta de dados foi realizada logo após o debriefing, por meio da "Escala de Avaliação do Debriefing Associado à Simulação". Resultados:o Valor Afetivo ocupou a maior média (4,61). No Valor Cognitivo, apresentaram-se pontuações superiores a 4,50, já o Valor Psicossocial pontuou a menor média $(4,32)$. Verificou-sea não normalidade em todas as variáveis $(\mathrm{p}=0,00)$.Quanto ao gênero ou à profissão, não houve diferença significativa entre as dimensões. Discussão: na literatura, o debriefing tem-se demonstrado um processo de aprendizagem autorreflexivo, oportunizando habilidades técnicas e não técnicas. Conclusão:o debriefing conduzido com bom julgamento, contribuiu para o socorrista integrar múltiplos saberes em valores afetivos, cognitivos e psicossociais e, assim, adquirir competências para o desfecho positivo da reanimação cardiopulmonar.
\end{abstract}

*Corresponding autho:

Thaísa Mariela Nascimento de Oliveira

Copyright (C) 2021, Thaísa Mariela Nascimento de Oliveira et al. This is an open access article distributed under the Creative Commons Attribution License, which permits unrestricted use, distribution, and reproduction in any medium, provided the original work is properly cited.

Citation: Thaísa Mariela Nascimento de Oliveira, Mara Solange Gomes Dellaroza and Eleine Aparecida Penha Martins, 2021. “Avaliação do debriefing na simulação realística da reanimação cardiopulmonar para profissionais socorristas", International Journal of Development Research, 11, (05), 4707747081 .

\section{INTRODUCTION}

$\mathrm{O}$ reconhecimento precoce e a intervenção imediata à vítima de parada cardiorrespiratória (PCR) por profissionais de saúde do âmbito intra-hospitalar ou pré-hospitalar ainda se apresenta como um cenário mundialmente desafiador, recheado de inexatidão, conforme postula a literatura e os núcleos de educação (ALMEIDA; DUARTE; MAGRO, 2019). Paralelamente, o seguimento de protocolos padronizados, o trabalho em equipe e o feedback desvelam os cenários tão complexos como a PCR (AHA, 2015). Além disso, a autoconfiança profissional, apreciada como habilidade não técnica, pode ser o "ingrediente" do sucesso ou de insucesso em consonância ao desejo de um desfecho positivo do caso (ALMEIDA; DUARTE; MAGRO, 2019). Para isso, estudantes e profissionais desfrutam da estratégia metodológica que utiliza a simulação realística como ensino-aprendizagem, com a possibilidade de erros dentro de cenário simulado, antes da prática real (SCLAFANI et al., 2019). Sendo assim, esse método, deve ser direcionado por modelos teóricos que guiem o facilitador a planejar, a executar e a avaliar a prática. De fato, na área da saúde um modelo bem estruturado tem sido utilizado: National League Nursing/Jeffries Simulation Theory, o qual orienta a simulação realística em cinco fases: objetivos; fidelidade; solução de problemas; apoio ao participante; e debriefing (JEFFRIES, 2012; JEFFRIES 2016).
Todas essas fases são consideradas valiosas, entretanto, o debriefing é apontado como o coração da estratégia, devendo ser conduzido embasado em objetivos preestabelecidos para cada cenário antes da execução da simulação, a fim de concretizar e de encorajar o pensamento crítico e reflexivo dos participantes (GORE; THOMSON, 2016). Durante o debriefing, os profissionais são encorajados a expressar seus sentimentos, suas incertezas e suas limitações de habilidades técnicas e não técnicas, possibilitando autoavaliação de seu planejamento e decisão e atitudes individuais ou em equipe para a construção do seu aprendizado (BORTOLATOMAJOR et al., 2019). Concomitantemente, o facilitador/professor se encarrega de conduzir o debriefing, por meio de planejamento e de seguimento de um modelo que norteie a sua condução e que melhor responda aos objetivos propostos antes, durante e após o cenário da simulação realística. Assim, apresenta-se o modelo de debriefing com "bom julgamento". A abordagem de "defriefing com bom julgamento" compõem-se de três elementos: no primeiro, o facilitador estimula as emoções que subsidiaram as ações durante a simulação, que, por sua vez, poderá receber ajuda para reformular os sentimentos que possam tornar-se medidas para alcançar resultados ainda melhores no futuro. Em segundo, aborda ações práticas e cognitivas desenvolvidas durante o cenário, mas sem impor julgamentos próprios como verdadeiros. Em vez disso, ele irá declarar subjetivamente sua visão, usando-a como "trampolim" para explorar a visão dos participantes. Por último, após ter compreendido a visão e as crenças dos participantes, o facilitador poderá concluir 
seus objetivos e caminhar para o desfecho ideal da resolução do cenário, que incluirá uma técnica de conversação objetiva com julgamentos subjetivos sob as ações e a reflexão dos participantes (RUDOLPH et al., 2006). Pesquisas que utilizarama simulação realística (GAMBOA et al., 2018; KLIPPEL et al., 2020; SULLIVAN et al., 2015; DELAC et al., 2013) destinando a profissionais já atuantes na área de saúde ainda são atípicas e quando realizadas o local de escolha é o ambiente intra-hospitalar. Todavia, apresentam-se quase que escassos os estudos que utilizam a simulação realística como ensino e treinamento destinado aos profissionais atuantes em serviços de urgência e de emergência no âmbito pré-hospitalar. Frente ao exposto, neste estudo objetivou-se avaliar a contribuição do debriefing associado à simulação realística da reanimação cardiopulmonar para profissionais socorristas.

\section{METHODOLOGY}

Trata-se de um estudo observacional transversal de abordagem quantitativa. Sua estrutura seguiu as diretrizes presentes na Declaração STROBE (Strengthening the Reporting of Observational Studies in Epidemiology). O estudo foi realizado em oito bases do Serviço de Atendimento Móvel de Urgência (SAMU) que contemplam as ambulâncias do Suporte Básico de Vida (SBV) localizadas na $18^{\circ}$ regional de saúde na região Norte do Paraná. Toda a população de 80 socorristas foi convidada a participar do estudo, que teve como único critério de exclusão o tempo mínimo de 6 meses na função, excluindo, por conseguinte, 10 participantes. Dos 70 socorristas, 15 foram descontinuados pois se apresentaram em férias ou em licença médica e, 5 por não comtemplarem todas as fases propostas. 9 não compareceram ao estudo, com três chances de participação. A amostra foi composta por 41 socorristas. Para realizar a coleta de dados, as pesquisadoras se deslocaram às 8 cidades, no período de janeiro a fevereiro de 2020. Foi enviado pelas pesquisadoras e reforçado pelo coordenador de enfermagem do SAMU, via aplicativo de celular móvel, o convite voluntário para a participação do estudo, bem como o agendamento dos dias e dos horários. A pesquisa de campo foi realizada somente após o esclarecimento aos participantes sobre os seus objetivos e a assinatura do Termo de Consentimento Livre e Esclarecido. Para participar dos três momentos que integram a simulação realística: pré-briefing e briefing; experiência da simulação implementada a partir do modelo de simulação da National League Nursing/Jeffries Simulation Theory (JEFFRIES et al.,2015; JEFFRIES, 2016); e debriefing, os socorristas foram divididos aleatoriamente em duplas, formadas por um condutor e um técnico de enfermagem, com a finalidade do retorno da circulação espontânea mediante a aplicação do SBV, seguindo as diretrizes da American Heart Association (AHA, 2020) à vítima adulta em PCR.

No pré-briefing foram apresentados os recursos disponíveis no cenário, a finalidade da estratégia metodológica e o tempo para a atuação. O briefing teve a duração de cinco minutos, e apresentou-se os objetivos a serem alcançados no cenário e foi entregue o caso clínico. Sequencialmente, a experiência da simulação teve início no interior da ambulância, após uma ligação simulada via central de regulação médica para uma ocorrência com a seguinte informação: "vítima do sexo masculino, sem resposta, com ausência de respiração e queixa anterior de dor no peito". Em seguida, a dupla de socorrista adentra, para a experiência da simulação, um cômodo elaborado dentro das próprias bases do SAMU e encontra a vítima, simulada por manequim de baixa fidelidade da Laerdal Little Anne ${ }^{\circledR}$, com sinais clínicos de PCR, dando-se início às manobras da RCP. Os comandos foram dados pelo instrutor da simulação. Além do manequim, o cenário contou com um DEA que indicava ritmo chocável após instalação, bolsa-válva-máscara, oxigênio portátil, celular para contatar a central de regulação e uma personagem que simulou um membro da família-ajuda com o histórico da vida, caso questionado. $\mathrm{O}$ cenário teve duração de oito minutos. $\mathrm{O}$ debriefing foi guiado por uma facilitadora com experiência em pré-hospitalar, com base no modelo do "bom julgamento" (RUDOLPH et al., 2006). Esse modelo de debriefing orienta, que o facilitador verbalize genericamente as condutas avaliadas durante o cenário, ao passo que convida o socorrista a expressar-se ativamente, valorizando o ponto de vista do participante e articulando as fragilidades observadas, como uma oportunidade de aprendizagem que favorece o pensamento reflexivo. $\mathrm{O}$ debriefing teve duração máxima de 20 minutos. Vale ressaltar que foi desenvolvido o teste piloto anterior à coleta de dados, aplicandose as três fases da simulação realística, com nove socorristas de uma base que não foi incluída no estudo. Por meio deste, encontraram-se e ajustaram-se fragilidades: aumento do tempo para o briefing, redução do tempo para resolução do cenário e inclusão de personagem (familiar) em cena para orientar o histórico da vítima. Os dados foram coletados individualmente, após a finalização de cada debriefing, por meio da Escala de Avaliação do Debriefing Associado à Simulação (EADaS), construída e validada para a língua portuguesa (COUTINHO, MARTINS, PEREIRA, 2014). Sua confiabilidade foi mensurada, retratando um coeficiente alfa de Cronbach de 0,899. A EADaS apresenta 34 itens de resposta tipo likert de 5 hipóteses: discordo completamente (1); discordo (2); nem concordo nem discordo (3); concordo (4), e concordo completamente (5). Possui, ainda, três dimensões: Dimensão Valor Psicossocial (13 itens), que compreende aspectos psicossociais durante a simulação; Dimensão Valor Cognitivo (9 itens), sobre a efetividade da construção dos saberes através do debriefing; e Dimensão Valor Afetivo (12 itens), referente aos sentimentos. No entanto, esta pesquisa contou com 33 itens, desconsiderando o item "25 - Reforçar a minha autonomia para atuar como futuro enfermeiro" do Valor Psicossocial, pois não se enquadrou com a realidade profissional do estudo. Os dados foram tabulados em planilha do Microsoft Excel® e analisados pelo programa Statistical Package for the Social Sciences (SPSS ${ }^{\circledR}$ ), versão 20.0, considerando o nível de significância de 5\%. Aplicou-se o teste de normalidade de Shapiro Wilk nas variáveis das três dimensões, em que se verificou a não normalidade em todas as variáveis $(\mathrm{p}=0,00)$. Também se realizou o teste não paramétrico de Man-Whitney, para constatar a existência de diferença significativa acerca dos resultados dentro de cada dimensão: entre os gêneros feminino e masculino e entre as profissões de técnico em enfermagem e condutor de ambulância. $\mathrm{Na}$ presente pesquisa, respeitaram-se o sigilo, a privacidade e os preceitos éticos, protegendo os direitos dos participantes, conforme a Resolução $n^{\circ} 466 / 2012$, e obtendo-se o aceite da coordenação do SAMU via carta ofício e aprovação pelo Comitê de Ética em Pesquisa da Universidade Estadual de Londrina, sob o parecer $n^{\circ} 3.572 .640$.

\section{RESULTS}

Compuseram o estudo 41 socorristas, dispostos em 20 técnicos de enfermagem e 21 condutores socorristas. $O$ sexo feminino (85\%) prevaleceu entre os técnicos em enfermagem, ao passo que o sexo masculino $(100 \%)$ predominou entre os condutores: Em relação à confiabilidade global da Escala de Avaliação do Debriefing Associado à Simulação (EADaS), o valor de alfa de Cronbach foi de 0,725 . Ao analisar o alfa para cada dimensão, atingiu-se 0,826 para o Valor Psicossocial, 0,709 para o cognitivo e 0,693 para o afetivo, o que revela boa consistência interna, semelhante à pesquisa que validou a escala (COUTINHO; MARTINS; PEREIRA, 2014). Na Tabela 1 ilustra-se a média geral de concordância da EADaS.

Tabela 1. Média geral de cada dimensão da EADas. Paraná, Brasil, 2020

\begin{tabular}{lllll}
\hline Dimensão & M & DP & Mín & Máx \\
\hline Valor Afetivo & 4,61 & 0,37 & 3,75 & 5,00 \\
Valor Cognitivo & 4,57 & 0,48 & 3,22 & 5,00 \\
Valor Psicossocial & 4,32 & 0,56 & 3,08 & 5,00 \\
\hline
\end{tabular}

Fonte: Elaborada pela autora

Nota. $\mathrm{M}=$ Média; $\mathrm{DP}=$ Desvio padrão; EADaS = Escala de Avaliação do Debriefing Associado à Simulação

Considerando as três dimensões da escala, o Valor Afetivo destacouse entre as dimensões, ocupando a maior média $(4,61)$, e todos os seus itens permaneceram acima da pontuação 4,0. No Valor 
Cognitivo, como média pontuação $(4,57)$, em que $86 \%$ de seus itens apresentaram-se com pontuação superior a 4,50. Já o Valor Psicossocial pontuou a menor média $(4,32)$, e, dentre os itens que o compõem, a maior se deu no item $23(4,68)$, e, a menor, no item 27 $(3,80)$. Por sua vez, na Tabela 2 exibe-se o valor médio de cada dimensão. Para um bom desempenho da escala, o esperado é que todas as médias sejam superiores a 3 pontos, isto é, superiores ao ponto médio da escala. Na dimensão Valor Afetivo, todos os itens foram invertidos para a análise estatística. A esse respeito, de acordo com Vieira e Dalmoro (2008), algumas escalas de avaliação são produzidas com itens cujo sentido inicial encontra-se oposto ao dos demais itens. Nesses casos, os autores responsáveis pelas escalas determinam que, para o cálculo da pontuação, o valor atribuído deverá ser invertido.
Psicossocial $(\mathrm{p}=0.14)$. Igualmente, entre as profissões também não foi encontrado diferença significativa: no Valor Afetivo $(\mathrm{p}=0.83)$, no Valor Cognitivo $(p=0.19)$ e no Valor Psicossocial $(p=0.23)$.

\section{DISCUSSION}

Na literatura são encontrados numerosos estudos (MAZZO et al., 2018; SOUZA et al., 2017; SILVA et al., 2020; BORTOLATOMAJOR et al., 2019; MARTINS, 2017; GORE; THOMSON, 2016; KAWAKAME; MIYADAHIRA, 2015) que, em sua maioria, abordam a simulação realística e o debriefing estruturado como método de ensino/aprendizagem destinado a estudantes na área da saúde, operando desfechos positivos ao futuro profissional daquele

Tabela 2. Disposição dos itens da EADaS de acordo com suas dimensões. Paraná, Brasil, 2020

\begin{tabular}{|c|c|c|c|c|}
\hline Dimensão & M & $\mathrm{DP}$ & Min & $\operatorname{Max}$ \\
\hline Valor Afetivo & 4,61 & 0,37 & 3,75 & 5,00 \\
\hline 2- Me envergonhar frente aos colegas pelos meus erros & 4,73 & 0,71 & 1,00 & 5,00 \\
\hline 5- Me deixar muito ansioso/estressado & 4,12 & 1,17 & 1,00 & 5,00 \\
\hline 9- Me humilhar frente aos outros & 4,78 & 0,69 & 1,00 & 5,00 \\
\hline 11- Me deixar em pânico só de pensar em ter de atuar de novo numa situação semelhante & 4,66 & 0,85 & 2,00 & 5,00 \\
\hline 14- Criar conflitos na equipe & 4,45 & 0,22 & 4,00 & 5,00 \\
\hline 15- Não querer participar em mais nenhuma simulação & 4,83 & 0,38 & 4,00 & 5,00 \\
\hline 18- Eu me sentir incompreendido & 4,38 & 1,00 & 1,00 & 5,00 \\
\hline 20- Eu me sentir desrespeitado & 4,63 & 0,92 & 1,00 & 5,00 \\
\hline 24- Eu sentir que foi uma perda de tempo & 4.93 & 0,26 & 4,00 & 5,00 \\
\hline 28- Eu ter medo de atuar no futuro em situações semelhantes & 4,70 & 0,61 & 2,00 & 5,00 \\
\hline 30- Bloquear o meu raciocínio & 4,56 & 0,84 & 1,00 & 5,00 \\
\hline 33- Baralhar as minhas ideias a respeito da atuação & 4,29 & 1,03 & 1,00 & 5,00 \\
\hline Valor Cognitivo & 4,57 & $\mathbf{0 , 4 8}$ & 3,22 & 5,00 \\
\hline 1- Estruturar o meu pensamento & 4,63 & 0,94 & 1,00 & 5,00 \\
\hline 3- Aprender mais & 4,61 & 1,00 & 1,00 & 5,00 \\
\hline 4- Me focar nos aspetos importantes da atuação & 4,61 & 0,70 & 2,00 & 5,00 \\
\hline 6- Refletir sobre as minhas competências & 4,41 & 0,85 & 1,00 & 5,00 \\
\hline 7- Identificar prioridades na atuação & 4,59 & 0,71 & 2,00 & 5,00 \\
\hline 8- Melhor identificar os recursos a utilizar na atuação & 4,41 & 0,95 & 1,00 & 5,00 \\
\hline 10- Aprofundar conhecimentos específicos relacionados com a atuação & 4,68 & 0,72 & 1,00 & 5,00 \\
\hline 12- Identificar aspetos que devo melhorar em atuações futuras & 4,63 & 0,70 & 2,00 & 5,00 \\
\hline 13- Desenvolver competências para a tomada de decisões acertadas & 4,73 & 0,50 & 3,00 & 5,00 \\
\hline Valor Psicossocial & 4,32 & $\mathbf{0 , 5 6}$ & 3,08 & 5,00 \\
\hline 16- Aumentar a minha confiança & 4,39 & 1,12 & 1,00 & 5,00 \\
\hline 17- Desenvolver competências de liderança & 3,88 & 1,25 & 1,00 & 5,00 \\
\hline 19- Aumentar o potencial em equipe & 4,51 & 0,90 & 1,00 & 5,00 \\
\hline 21- Eu me sentir realizado & 4,51 & 0,68 & 3,00 & 5,00 \\
\hline 22- Reforçar a minha iniciativa em situações futuras & 4,61 & 0,63 & 3,00 & 5,00 \\
\hline 23- Desenvolver a relação de ajuda & 4,68 & 0,47 & 4,00 & 5,00 \\
\hline 25- Identificar dificuldades na minha atuação & 4,18 & 1,17 & 1,00 & 5,00 \\
\hline 26- Promover a autoconsciência & 4,41 & 0,71 & 3,00 & 5,00 \\
\hline 27- Eu me sentir no centro do processo formativo & 3,80 & 1,05 & 1,00 & 5,00 \\
\hline 29- Melhorar a minha capacidade de gerir emoções & 3,98 & 1,19 & 1,00 & 5,00 \\
\hline 31- Eu sentir orgulho por ser capaz de executar muitas intervenções corretamente & 4,51 & 0,87 & 1,00 & 5,00 \\
\hline 32- Eu sentir que o professor tem interesse genuíno no meu desenvolvimento profissional & 4,44 & 1,05 & 1,00 & 5,00 \\
\hline
\end{tabular}

Fonte: Elaborada pela autora

Nota. $\mathrm{N}=\mathrm{M}=$ Média; $\mathrm{DP}=$ Desvio padrão; EADaS = Escala de Avaliação do Debriefing Associado à Simulação.

Considerando as três dimensões da escala, na dimensão Valor afetivo, destaca-se a média dos itens: Eu sentir que foi uma perda de tempo $(4,93)$; Não querer participar em mais nenhuma simulação $(4,83)$; Me humilhar frente aos outros $(4,78)$; Me envergonhar frente aos colegas pelos meus erros $(4,73)$; e $\mathrm{Eu}$ ter medo de atuar no futuro em situações semelhantes $(4,70)$, com pontuação igual o superior a 4,70. Na dimensão Valor Cognitivo, as pontuações se apresentaram acima de 4 pontos, sendo a maior pontuada no item - Desenvolver competências para a tomada de decisões acertadas" $(4,73)$. Os itens Estruturar o meu pensamento $(4,63)$; Identificar aspectos que devo melhorar em atuações futuras $(4,63)$ obtiveram pontuações iguais, bem como os itens - Aprender mais $(4,61)$ e, Me focar nos aspectos importantes da atuação $(4,61)$, também com médias similares. Já no Valor psicossocial, encontrou-se a menor média dentre as três dimensões, caracterizadas pelos itens: Melhorar a minha capacidade de gerir emoções $(3,98)$; Desenvolver competências de liderança $(3,88)$; e Eu me sentir no centro do processo formativo $(3,80)$. No tocante ao gênero, não houve diferença significativa entre as médias: do Valor Afetivo $(\mathrm{p}=0.40)$, do Valor Cognitivo $(\mathrm{p}=0.39)$ e do Valor que a pratica. Pesquisas que utilizam da mesma estratégia (GAMBOA et al., 2018; KLIPPEL et al., 2020; SULLIVAN et al., 2015; DELAC et al., 2013) mas a destinando a profissionais já atuantes na área de saúde são atípicas e, em grande parte, aplicadas em ambiente intra-hospitalar. Os resultados também têm se mostrado satisfatórios a esse público e importantes no desenvolvimento de suas habilidades técnicas e não técnicas, com ganho individual e em equipe. Todavia, apresentam-se quase que escassos os estudos que utilizam a simulação realística como ensino e treinamento destinado aos profissionais atuantes em serviços de urgência e de emergência no âmbito pré-hospitalar. No presente estudo, dentre a média de cada dimensão, o valor afetivo destacou-se com a maior pontuação, seguido do valor cognitivo e do valor psicossocial. Corroborando esses resultados, encontrou-se um realizado por Silva et al. (2020) com estudantes de graduação em Enfermagem, que, aplicando a mesma escala EADaS, atingiu pontuações semelhantes. Por outro lado, Bortolato-Major et al. (2019), com o mesmo objetivo de avaliar a contribuição do debriefing com a utilização da escala EADaS, obtiveram resultados que diferem deste estudo, pois a dimensão mais 
bem pontuada pelos graduandos em enfermagem foi a de Valor Cognitivo. Com a maior média dentre as três dimensões, evidenciouse entre os socorristas a dimensão do Valor Afetivo. Vale relembrar que os itens dessa dimensão são invertidos no sentido de suas respostas. Nos itens que avaliavam um possível sentimento de desrespeito ou incompreensão pelos profissionais durante a participação no debriefing, os resultados apontam que os socorristas não se consideraram desrespeitados ou incompreendidos. Logo, a elevada média dessa dimensão explica que ter afetividade é um dos pontos de equilíbrio para que o profissional se sinta realizado como pessoa (LIMA et al., 2018).

Sequencialmente, ressalta-se a pontuação dos itens que remetem o sentimento expresso pelo socorrista, em não se sentir humilhado, envergonhado, ou em pânico para uma nova participação das fases que compõem a simulação realística. Tais dados sugerem, que o debriefing realizado com "bom julgamento", instruído por Rudolph et al. (2006), contribuiu para o desenvolvimento do socorrista, sem humilhação ou julgamentos ofensivos. Cabe salientar que esses profissionais já se encontram atuantes em cenários reais de RCP, com o conhecimento prévio do protocolo avaliado durante a simulação, porém podendo apresentar-se desatualizados ou mesmo não praticantes. Nesse tipo de debriefing, o socorrista teve um espaço reservado, que não o cenário da simulação, para organizar a autorreflexão sobre a ação conduzida pela dupla, refletindo, assim, em novos entendimentos sobre sua atuação no cenário, o qual servirá para o aperfeiçoamento na prática clínica futura, em que os resultados demonstraram o interesse do socorrista de participar novamente em futuros treinamentos e da segurança para atuar em situações semelhantes em cenário real, pois de acordo com Coutinho, Martins, Pereira (2016), os participantes precisam sentir-se confortáveis o suficiente para fazer perguntas e autoavaliar-se, sem o medo de serem constrangidos, identificando seus próprios erros ao conectar a prática à teoria e ao desenvolvimento de habilidades de trabalho em equipe. Neste sentido, se o debriefing não tiver uma boa condução, todo o ganho de aprendizado pode ser prejudicado, levando à diminuição do desempenho clínico do participante, à perda da autorreflexão e a dificuldades na relação com o facilitador (PALAGANAS; FEY; SIMON, 2016), o que não foi o caso deste estudo, demonstrado pela percepção dos socorristas em não concordar que o debriefing tenha criado conflitos na equipe ou lhes causado ansiedade e estresse.

Na dimensão Valor Cognitivo, o item que melhor pontuou se remete ao desenvolvimento de competências para a tomada de decisões acertadas, resultado este, que vai ao encontro do estudo realizado por Klippel et al. (2020) no Rio de Janeiro, com 103 enfermeiros residentes, os quais referiram ter adquirido maior consciência de suas atribuições com o debriefing, após simulação de vítimas cardíacas, com evolução positiva em relação à tomada de decisão e à resolução de problemas, além de ter desenvolvido maior confiança em sua jornada profissional, pois aprenderam a controlar seus medos e suas ansiedades. Outros itens do valor cognitivo, demonstraram a capacidade do debriefing em estruturar o pensamento, com foco nos aspectos importantes da atuação que tem por finalidade o melhor desempenho em atuações futuras. O profissional que sabe "tirar lições da experiência" tem dom de usufruir de sua prática como uma oportunidade de saberes, que não se contenta apenas com ações, mas está à procura de teorias e de embasamentos que validem sua conduta (BORTOLATO-MAJOR et al., 2019). Acredita-se que a dimensão cognitiva, está vinculada à oportunidade que o socorrista teve de imergir na experiência tanto da simulação do atendimento a vítima de PCR, quanto do debriefing conduzido com "bom julgamento" pela facilitadora, observado pela pontuação dos itens que remetem a identificação da necessidade refletir sobre a competência desempenhada e em saber utilizar os materiais disponíveis no cenário. Contudo, os valores analisados nessa dimensão transparecem que o diálogo durante o debriefing foi processado e teve como finalidade a percepção, a integração e a compreensão adequada aos estímulos do ambiente, levando o socorrista a refletir e a avaliar o seu autodesempenho na ação de condutas adequadas. Na dimensão Valor Psicossocial a média encontrada nos itens que versaram a concordância da capacidade do debriefing em reforçar a iniciativa do profissional para situações futuras e em aumentar a sua confiança, corroboram com um estudo conduzido com 250 profissionais de saúde de um hospital norte-americano, no qual foi realizada uma avaliação do nível de confiança antes e depois de uma simulação de RCP com uso do DEA. Neste, os participantes expressaram mais confiança ao realizar o procedimento após a simulação, além da melhoria significativa no tempo da atuação da RCP e da desfibrilação precoce (DELAC et al., 2013).

Outros itens demonstrados pelo valor psicossocial, apontam o aumento do potencial do trabalho em equipe e, a realização pessoal por sentir-se capaz de executar intervenções corretamente, confirmam que a sintonia da simulação atrelada ao debriefing, proporciona a aquisição da competência de trabalhar em equipe, função esta que envolve os saberes: comunicação, cooperativismo, autorreflexão e decisão coletiva (DELAC et al., 2013). O profissional que sabe liderar para trabalhar em equipe tem a habilidade de construir pontes e de solucionar problemas, pois está aberto a contribuições do saber coletivo (PERRENOUD, 2013). As pontuações elevadas do Valor Psicossocial indicam que os socorristas percebem no debriefing um melhor equilíbrio psicológico e emocional, pessoal ou em equipe, e uma ferramenta de aprendizado contínuo das melhorias em habilidades e em atitudes, as quais reforçam a iniciativa de situações futuras por: aumentar a confiança, reforçar a iniciativa em situações futuras, identificar dificuldades na atuação, promover a autoconsciência e sentir que o professor tem interesse genuíno no meu desenvolvimento profissional (MARTINS, 2017; BORTOLATO-MAJOR et al., 2019). As menores pontuações do valor psicossocial demostradas pelos itens que abordaram a capacidade do debriefing em gerir emoções, desenvolver o papel de liderança e sentir-se no centro do processo formativo, também foram observadas como fragilidade em estudo com alunos de graduação em enfermagem (SILVA et al., 2020). Ainda assim, o fato de essa estratégia exigir dos profissionais serem eles próprios os responsáveis pelo processo de aprendizagem provoca-os para que tenham maior iniciativa, capacidade para autorreflexão, gestão de emoções e comportamentos que não tenham sido, ao longo do seu processo formativo profissional, uma atuação constante (COUTINHO; MARTINS; PEREIRA, 2016; SILVA et al., 2020), o que pode justificar os valores mais baixos encontrados nessa dimensão e nas outras. Em geral, diversos autores (JERSBY et al., 2017; BORTOLATO-MAJOR et al., 2019; SILVA et al., 2020; KLIPPEL et al., 2020) discursam sobre os privilégios do debriefing. Em vista disso, o presente estudo vem concretizar essas conclusões e materializar seu impacto positivo na aquisição de habilidades, de autonomia e de segurança para a tomada de decisão. A fase do debriefing logo após a simulação realística viabiliza um processo de aprendizagem autorreflexiva, oportunizando habilidades múltiplas (JEFFRIES, 2016). Nesta pesquisa, essas habilidades estão retratadas nos valores afetivos, cognitivos e psicossociais.

\section{CONCLUSION}

Acredita-se que a escolha do modelo do debriefing foi o que possibilitou a prática reflexiva para integrar múltiplos saberes, valorizando o ponto de vista do socorrista ao expressar-se e articulando de forma conjunta as fragilidades cometidas como uma oportunidade de aprendizagem sem julgamentos. O fato do debriefing guiado com "bom julgamento" os provocarem para que eles próprios assumam o papel da autorreflexão sobre os acertos ou fragilidades de suas ações desempenhadas no cenário, foi considerado como uma limitação deste estudo, visto que dentro do processo de trabalho, metodologias ativas ainda são pouco utilizadas, prevalecendo o método de ensino/treinamento tradicional. No que diz respeito às três dimensões, notou-se, no Valor Psicossocial, o aumento da confiança e de realização profissional, pois os participantes puderam identificar e revisar iniciativas na atuação em equipe para situações futuras. Observou-se, no valor Cognitivo, o aumento do potencial de competência para a tomada de decisões e para o aprofundamento no conhecimento específico. Por fim, no tangente ao Valor Afetivo, dimensão mais bem pontuada pelos socorristas, transpareceu a 
eficácia do método para otimizar o tempo do aprendizado e o querer participar frequentemente dessa estratégia. Então, pode-se concluir que os socorristas do suporte básico de vida do serviço de atendimento móvel de urgência consideraram o processo de debriefing como fator de grande contribuição para o seu aprendizado e sua atualização profissional, tendo a possibilidade de retomar as habilidades $\mathrm{e}$ as atitudes desenvolvidas durante $\mathrm{o}$ atendimento à vítima de parada cardíaca e de readequá-las. Sugere-se que os serviços de urgência e emergência adotem a capacitação utilizando o método da simulação realística em suas atividades diárias.

\section{REFERENCES}

AHA. American Heart Association. Highlights of the 2015 American Heart Association guidelines update for CPR and ECC. 2015. Disponível em: https://eccguidelines.heart.org/wpcontent/uploads/2015/10/2015-AHA-Guidelines-HighlightsEnglish.pdf.

Almeida MN, Duarte TTP, Magro MC. Simulação in situ: ganho da autoconfiança de profissionais de enfermagem na parada cardiopulmonar. Revista Rene, Fortaleza, v. 20, p. e41535, 2019.

Bortolato-major C. et al.Avaliação do debriefing na simulação clínica em enfermagem: um estudo transversal. Revista Brasileira de Enfermagem, v. 72, n. 3, p. 825-831, 2019.

BRASIL. Conselho Nacional de Saúde. Resolução n. ${ }^{\circ}$ 510, de 7 abril de 2016. Dispõe sobre as normas aplicáveis a pesquisas em Ciências Humanas e Sociais. Diário Oficial da União: seção 1, Brasília, DF, n. 98, p. 44, 24 maio 2016. Disponível em: http://www.conselho.saude.gov.br/resolucoes/2016/Reso510.pdf

Coutinho VRD, Martins JCA,Pereira MFCR. Construção e validação da Escala de Avaliação do Debriefing Associado à Simulação (EADaS). Revista de Enfermagem Referência, v. 4, n. 2, p. 4150, 2014.

Delac $\mathrm{K}$ et al. Five alive: using mock code simulation to improve responder performance during the first 5 minutes of a code. Critical Care Nurse, v. 36, n. 2, p. 244-250, 2013.

Gamboa OA et al. Evaluation of two strategies for debriefing simulation in the development of skills for neonatal resuscitation: a randomized clinical trial. BMC Research Notes, v. 11, p. 739, 2018.

Gore $\mathrm{T}$, Thomson W. Use of simulation in undergraduate and graduate education. AACN Advanced Critical Care, v. 27, n. 1, p. 86-95, 2016.

Jeffries PR. Simulation in nursing education: from conceptualization to evaluation. $2^{\text {nd }}$ ed. New York: National League for Nursing, 2012.

Jeffries PR. The NLN Jeffries simulation theory. Wolters Kluwer,New York: National League for Nursing, 2016.
Jersby MA,et al. The use of multiple-criteria decision-making theory to measure students' perceptions of high-fidelity simulation. BMJ Simulation and Technology Enhanced Learning, v. 3, n. 3, p. 88-93, 2017.

Kawakame PMG, Miyadahira AMK. Avaliação do processo ensinoaprendizagem de estudantes da área da saúde: manobras de ressuscitação cardiopulmonar. Revista da Escola de Enfermagem da USP, v. 49, n. 4, p. 657-664, 2015.

Klippel C,et al. A contribuição do debriefing no ensino baseado em simulação. Revista de Enfermagem UFPE on line, v. 14,2020.

Lima MN,et al. Retenção da aprendizagem após treinamento em Suporte Básico de Vida com uso de simulação de baixa fidelidade em uma unidade hospitalar odontológica. Scientia Medica, v. 28, n. 1, 2018.

Martins JCA. Aprendizagem e desenvolvimento em contexto de prática simulada. Revista de Enfermagem Referência, n. 12, p. 155-162, 2017.

Mazzo A,et al. Implicações do uso de som e imagem na avaliação de debriefing. Revista Mineira de Enfermagem, v. 23, p. e-1159, 2018.

Palaganas JC, Fey M, Simom R. Structured debriefing in simulationbased education. Advenced Critical Care, v. 27, n. 1, p. 78-85, 2016.

Perrenoud P. Desenvolver competências ou ensinar saberes: a escola que prepara para a vida. Porto Alegre: Penso, 2013.

Rudolph JW,et al. There's no such thing as "nonjudgmental" debriefing: a theory and method for debriefing with good judgment. Simulation Healthcare, v. 18, n. 1, p. 49-55, 2006.

Saramma PP,et al. Assessment of long-term impact of formal certified cardiopulmonary resuscitation training program among nurses. Indian Journal of Critical Care Medicine, v. 20, n. 4, p. $226 \square 232,2016$.

Sclafani A,et al. Internal medicine residents' exposure to and confidence in managing hospital acute clinical events.Journal Hosital Medicine, v. 14, n. 4, p. 218-223, 2019.

Silva MAN, et al. Avaliação do debriefing estruturado como estratégia pedagógica em enfermagem de saúde familiar. Revista de Enfermagem Referência, v. 5, n. 2, p. e19081, 2020.

Souza JMO,et al. Debriefing como ferramenta de avaliação qualitativa no ensino simulado. Atas- Avaliação Qualitativa em Saúde, v. 2, p. 841-848, 2017.

Sullivan NJ,et al. Simulation exercise to improve retention of cardiopulmonar resuscitation priorities for in-hospital cardiac arrests: a randomized controlled trial. Resuscitation, v. 86, p. 8$13,2015$.

Vieira KM,Dalmoro M. Dilemas na construção de escalas tipo Likert: o número de itens e a disposição influenciam nos resultados? In: ENCONTRO DA ANPAD, 32., 2008, Rio de Janeiro. Anais [...]. Rio de Janeiro: Windsor Barra Hotel \& Congressos, 2008. Disponível em: http://www.anpad.org.br/admin/pdf/EPQA1615.pdf. Acesso em: 21 set. 2020. 